\title{
BGP-15 Protects Mitochondria in Acute, Acetaminophen Overdose Induced Liver Injury
}

\author{
Farkas Sarnyai ${ }^{1} \cdot$ Timea Szekerczés $^{2}$ - Miklós Csala ${ }^{1}$ • Balázs Sümegi ${ }^{3}$ - András Szarka ${ }^{4}$. \\ Zsuzsa Schaff $^{2}$ (1) $\cdot$ József Mandl $^{1}$
}

Received: 19 March 2019 / Accepted: 13 August 2019 / Published online: 8 November 2019

(C) The Author(s) 2019

\begin{abstract}
Acetaminophen (APAP) induced hepatotoxicity involves activation of c-Jun amino-terminal kinase (JNK), mitochondrial damage and ER stress. BGP-15, a hydroximic acid derivative, has been reported to have hepatoprotective effects in APAP overdose induced liver damage. Effect of BGP-15 was further investigated on mitochondria in APAP-overdose induced acute liver injury in mice. We found that BGP-15 efficiently preserved mitochondrial morphology, and it caused a marked decrease in the number of damaged mitochondria. Attenuation of mitochondrial damage by BGP-15 is supported by immunohistochemistry as the TOMM20 label and the co-localized autophagy markers detected in the livers of APAP-treated mice were markedly reduced upon BGP-15 administration. This effect, along with the observed prevention of JNK activation likely contribute to the mitochondrial protective action of BGP-15.
\end{abstract}

Keywords Mitochondrium · Acetaminophen $\cdot$ Liver injury $\cdot$ BGP-15 $\cdot$ Reduced glutathione $\cdot$ Jun-kinase

\section{Introduction}

Acetaminophen (N-acetyl-p-aminophenol, APAP) is the most common painkiller, antifebrile and one of the most frequently used drugs in the world [1]. However, APAP is a dosedependent hepatotoxin, with approximately $50 \%$ of all acute liver failure cases in the USA and UK attributed to APAP overdose [2]. The toxicity of APAP is a complicated process and it is not fully understood. Several organelles and

Farkas Sarnyai and Timea Szekerczés contributed equally to this work.

Zsuzsa Schaff

schaff.zsuzsa@med.semmelweis-univ.hu

1 Department of Medical Chemistry, Semmelweis University, Budapest, Hungary

2 2nd Department of Pathology, Semmelweis University, Üllői út 93, Budapest H-1091, Hungary

3 Department of Biochemistry and Medical Chemistry University of Pécs, Pécs, Hungary

4 Department of Applied Biotechnology and Food Science, Laboratory of Biochemistry and Molecular Biology, Budapest University of Technology and Economics, Budapest, Hungary molecules have been shown to contribute to APAP toxicity. A series of experimental and clinical data have been published on the pathomechanism of APAP-induced liver injury [3-6]. At a cellular level, it is generally accepted that mitochondrial damage is a key element of the pathology induced by APAP overdose [7, 8], however, endoplasmic reticulum (ER) stress also develops [4]. The mitochondrial injury occurs in at least two steps [3]. Conversion of APAP to N-acetyl-pbenzoquinone imine (NAPQI) is catalyzed mainly by CYP2E1 in hepatocytes [9]. NAPQI causes oxidative stress through increased ROS generation and adduct formation with proteins and glutathione. The formation of mitochondrial protein adducts due to APAP overdose induced NAPQI formation plays a crucial role in the initiation of APAP induced liver injury $[8,10,11]$. Formation of the aforementioned protein adducts is involved in the inhibition of mitochondrial respiration [12], the subsequent formation of ROS [13] and peroxynitrite in mitochondria [14]. Furthermore, the role of the initial increase in ROS formation upon NAPQI synthesis stimulates intracellular signaling processes [11]. Oxidative stress triggers MAP kinase cascades that lead to phosphorylation and activation of c-Jun amino-terminal kinase (JNK), which in turn is connected to the initial mitochondrial dysfunction. Activation and mitochondrial translocation of JNK in the liver has also been shown to play a central role in the 
pathomechanism of APAP toxicity [15]. JNK amplifies the already existing mitochondrial oxidant stress and largely contributes to cell death by stimulating MOMP (mitochondrial outer membrane permeabilization) and MPT (mitochondrial permeability transition) [16], which leads to the collapse of mitochondrial membrane potential and to the release of various proapoptotic mediators. Nuclear translocation of AIF (apoptosis-inducing factor) and endonuclease $\mathrm{G}$ from the mitochondria is a well-known event of caspase-independent apoptosis, and it was indeed demonstrated in livers of APAPtreated animals $[5,17]$.

BGP-15 is a hydroximic acid derivative. Its various experimental effects have been demonstrated in a series of different animal models and also in cell cultures. These are protective effects influencing among others heart, skeletal muscle, liver, oocytes, skin and show the involvement of mitochondria [5, 18-24]. Hindrance of ROS elevation and also moderation in JNK activation by BGP-15 have been shown in different experimental models [18]. Phase II clinical observations suggest its antidiabetic effect [25].

We have published protective effects by BGP-15 in acute APAP induced liver injury; it largely counteracted MOMP [5]. In addition, mitochondrial dysfunction and even ER stress were also affected by BGP-15 in different experimental systems $[19,22,23]$. Therefore, the effect of BGP-15 was further investigated focusing mainly on morphological signs of the involvement of mitochondria and on JNK activation. Protective mitochondrial effects of BGP-15 in APAP overdose induced liver injury have been shown on various pathomorphological phenomena, and JNK activation.

\section{Materials and Methods}

In this report, in vivo hepatoprotective effects of BGP15 in APAP-induced liver injury are shown in mice. The animals (male NMRI BR SPF mice of 25-30 g body weight) were starved for $18 \mathrm{~h}$ prior to the administration of a single sub-lethal dose of APAP $(450 \mathrm{mg} / \mathrm{kg}$ bw, i.p.). APAP was added with or without $100 \mathrm{mg} / \mathrm{kg}$ body weight BGP-15; the controls received vehicle or BGP-15 only. The mice were sacrificed after $6 \mathrm{~h}$, blood samples were withdrawn and the livers were dissected (for Western blot, RT-PCR, electron microscopy, immunohistochemistry and metabolic analysis). These studies were conducted in accordance with the laws and regulations of governing authorities, and they were approved by the Epidemiology and Animal Protection Division of the Governmental Directorate of Food Chain Safety and Animal Health.

\section{Histology, Immunohistochemistry}

Samples from mice livers were fixed in formalin and embedded in paraffin (FFPE). 3-4 $\mu \mathrm{m}$ thick sections were prepared and stained by hematoxylin-eosin (H\&E).

\section{Immunohistochemistry (IH)}

FFPE sections were used after deparaffinization and endogenous peroxidase blocking applying $1 \%$ hydrogen peroxide. For retrieving antigens Target Retrieval Solution (DAKO, Glostrup, Denmark) was used for $30 \mathrm{~min}$ in microwave oven, followed by incubation with the primary antibodies against TOMM20 (mAb, 1:200, Santa Cruz Biotechnology Inc., CA, USA), JNK (Phospho-SAPK/JNK, Thr183/Tyr185, 81E11, rabbit mAb, 1:100, Cell Signaling Technology Inc., Leiden, The Netherlands), Beclin1/ATG6 (1:200, Novus Biologicals Europe, Cambridge, UK), LC3 (1:200, polyclonal rabbit NB-100-2331 Novus Biologicals Europe) and p62 (1:1000, monoclonal mouse ab56416, Abcam, Cambridge, MA, USA).

The reactions were carried out with Ventana Benchmark XT automated immunohistochemical staining system (Ventana Medical System Inc., Tucson, AZ, USA) with HRP Multimer based, biotin-free detection technique according to the protocol provided by the manufacturer. Reagents and secondary antibodies were obtained from Ventana and the reactions were visualized by UltraView ${ }^{\mathrm{TM}}$ Universal DAB Detection Kit (Ventana). Nuclear staining was performed using hematoxylin. For negative control, primary antibodies were substituted with Antibody diluent (Ventana).

\section{Electron Microscopy}

Samples from liver were fixed in $2.5 \%$ glutaraldehyde, followed by $1 \% \mathrm{OsO} 4$. After dehydration in graded ethanol, the samples were embedded into epoxy resin. Semithick sections were used for the selection of the proper areas, followed by ultrathin sectioning. The uranyl acetate and lead citrate contrasted sections were analyzed and photographed in a JEM 1011 electron microscope (JEOL).

\section{Sample Preparation and Western Blot Analysis}

Approximately $1 \mathrm{mg}$ of the liver was homogenized with Elvehjem tissue grinder in lysis buffer. The lysis buffer contained $0.1 \%$ SDS, $5 \mathrm{mM}$ EDTA, $150 \mathrm{mM} \mathrm{NaCl}, 50 \mathrm{mM}$ Tris, $1 \%$ Tween 20, $1 \mathrm{mM} \mathrm{Na3VO4,} 1 \mathrm{mM}$ PMSF, $10 \mathrm{mM}$ benzamidine, $20 \mathrm{mM} \mathrm{NaF}, 1 \mathrm{mM}$ pNPP and protease inhibitor cocktail. The lysates were centrifuged with benchtop centrifuge $\left(10 \mathrm{~min}, 10.000 \mathrm{rpm}, 4{ }^{\circ} \mathrm{C}\right)$. Protein concentration of the supernatant was measured with Pierce BCA Protein Kit Assay (Thermo Scientific), and then stored on $-20{ }^{\circ} \mathrm{C}$ until use. 
Fig. 1 Histology of mouse livers $6 \mathrm{~h}$ after treated with APAP (a), with BGP15 (b), untreated control (c) and APAP+BGP15treatment $(\mathbf{d})$. Severe cellular injury in APAP-treated livers, while no alterations in the other samples (formalin fixation, paraffin embedding, hematoxylin and eosin staining). (a, c, d: 150X, b: $250 \mathrm{X})$
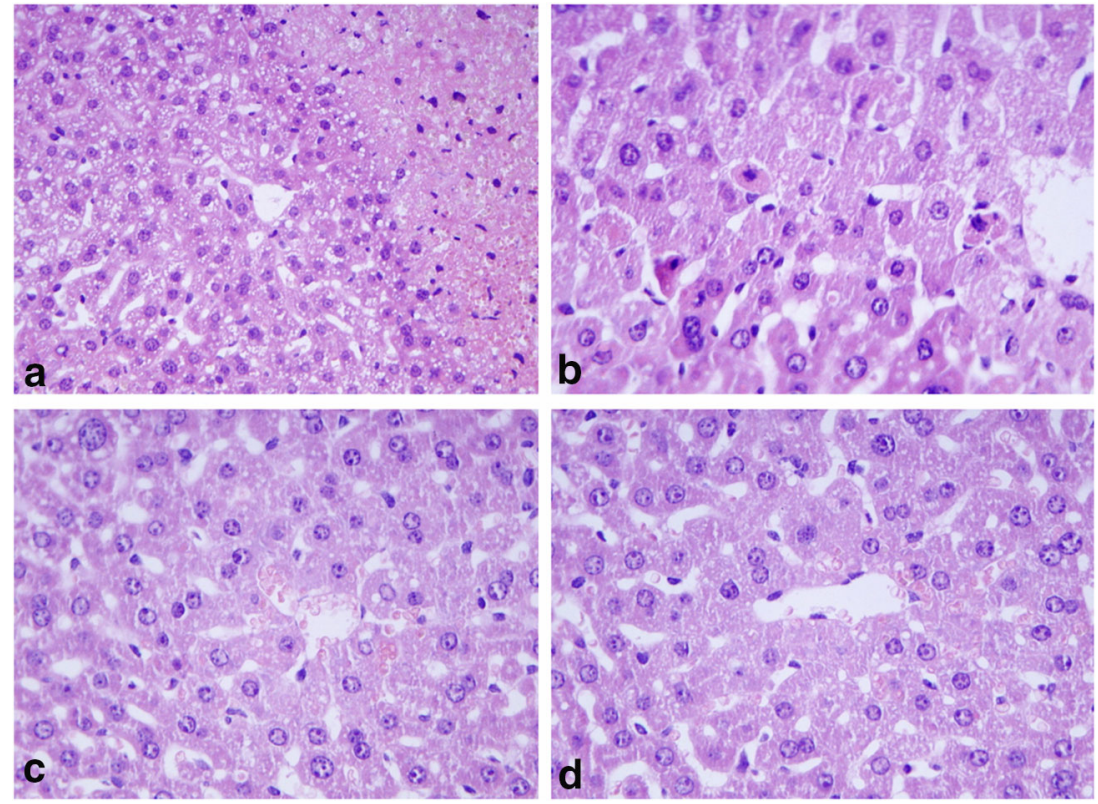

Samples (50 mg protein) were electrophoresed on $10 \%$ SDS polyacrylamide gels and transferred to PVDF membrane (Millipore). Primary and secondary antibodies were applied overnight at $4{ }^{\circ} \mathrm{C}$ and for $1 \mathrm{~h}$ at room temperature, respectively. Equal protein loading was validated by detection of GAPDH as a constitutively expressed reference protein. Mouse monoclonal anti-GAPDH (Santa Cruz, sc-32,233) antibody was used at 1:20,000 dilution. Primary antibodies: rabbit anti-phospho-SAPK/JNK (THR183/Tyr185) antibody (\#9251S), anti-SAPK/JNK antibody (\#9252S). Secondary antibodies: Horseradish peroxidase (HRP)-conjugated goat antirabbit IgG-HRP (\#7074) from Cell Signaling and donkey antigoat IgG-HRP (sc-2020) from Santa Cruz. HRP was detected with chemiluminescence using Western Lightning Plus-ECL (Perkin Elmer).

\section{Results}

\section{Effect of BGP-15 Administration on APAP- Induced Liver Injury Seen by Light and Electron Microscopy and Immunohistochemistry}

After $6 \mathrm{~h}$ of APAP administration, severe liver cell injury, mainly in centrolobular localization was observed (Fig.1a). In contrast, no sign of liver injury as necrosis or apoptosis was present in the BGP15-treated (Fig.1b) or in the control (Fig. 1c) and APAP+BGP16-treated (Fig.1d) samples. The severe cellular injury was well presented by electron microscopy (Fig. 2). Distorted, vacuolated mitochondria were observed, many with lost cristae (Fig. 2a), some of them localized in lysosomes. The BGP-15-treated (Fig. 2b), control (Fig. 2c) and APAP+BGP-
Fig. 2 Electron micrographs of mouse livers treated with APAP (a), BGP15 (b), untreated control (c) and APAP+BGP15 (d) for $6 \mathrm{~h}$. Severely degraded organelles, some mitochondria lost their cristae, mitophagy in a damaged hepatocyte after APAP-treatment (a). Hepatocyte with large number of mitochondria with normal ultrastructure in BGP15treated (b), control (c) and APAP+BGP15-treated liver (d). (Glutaradehyde+OsO4 fixation, resin embedding)
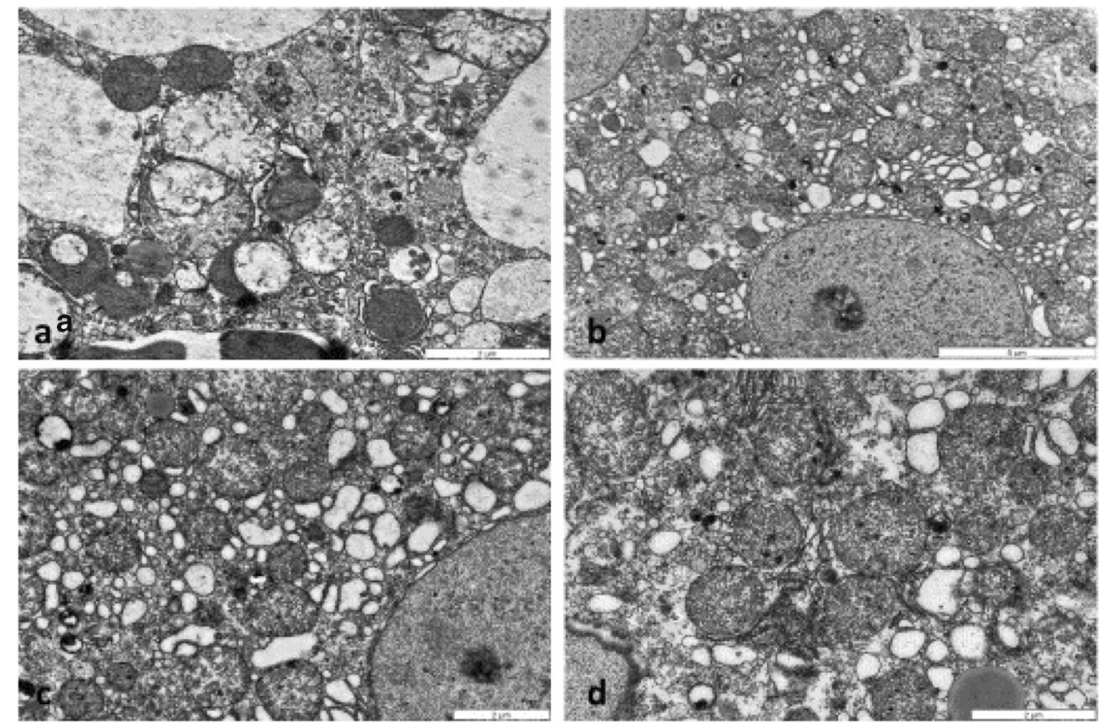
Fig. 3 Immunohistochemical reaction with TOMM20 antibody. Mice were treated with APAP $(450 \mathrm{mg} / \mathrm{kg}$ ) and BGP

$(100 \mathrm{mg} / \mathrm{kg})$ alone, or in combination for $6 \mathrm{~h}$. Intensive granular reaction is detected in the hepatocytes after APAP-treatment in the centrolobular area (a). No reaction in the BGP15-treated (b) and control livers (c) and few granules can be seen after APAP+ BGP15 treatment (d). (formalin fixation, paraffin embedding, hematoxílin-staining) (150X)
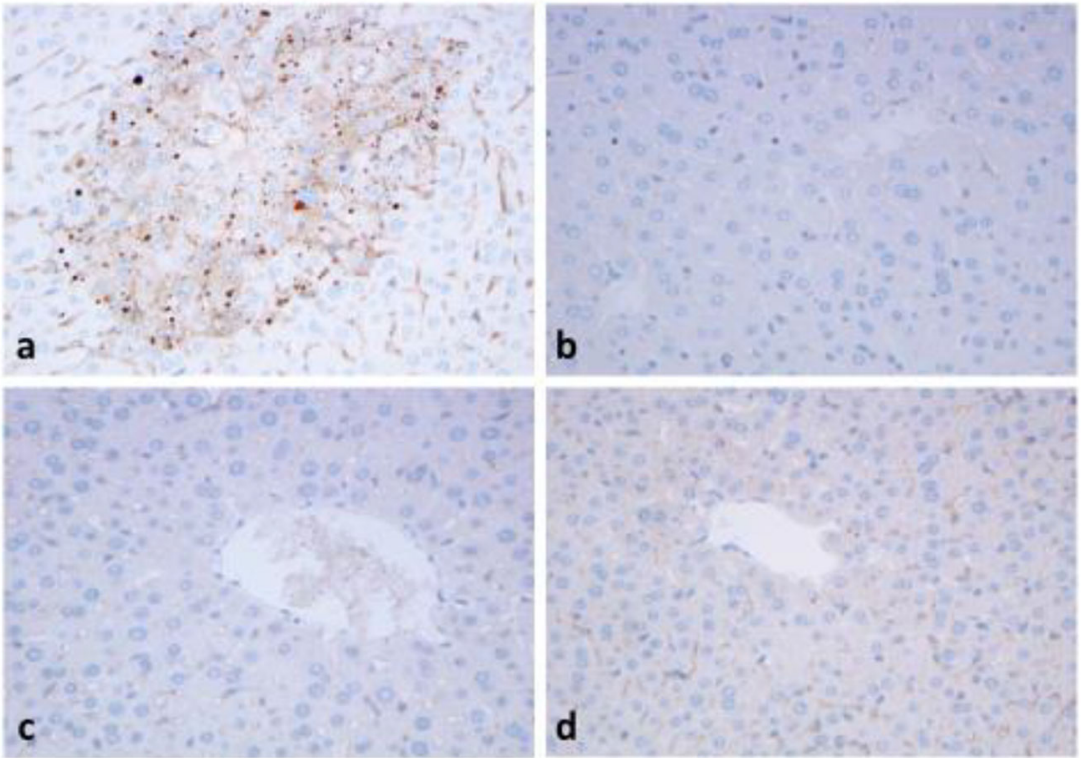

15-treated (Fig.2d) hepatocytes demonstrated normal mitochondrial morphology. Immunohistochemical reactions using anti-TOMM20 antibody, demonstrated large numbers of positively-stained brown granules with variable sizes in the injured hepatocytes after APAP-administration (Fig. 3a), mainly located in the centrolobular zones, while the BGP-15-treated
Fig. 4 Strong granular immunohistochemical reaction with antibodies to TOMM20 (a), beclin1 (b), LC3 (c) and p62 (d) after APAP-treatment. No reaction in the control, untreated livers (e) and few granules can be seen after APAP+BGP15 treatment (f). (formalin fixation, paraffin embedding, hematoxylin-staining). (250X)
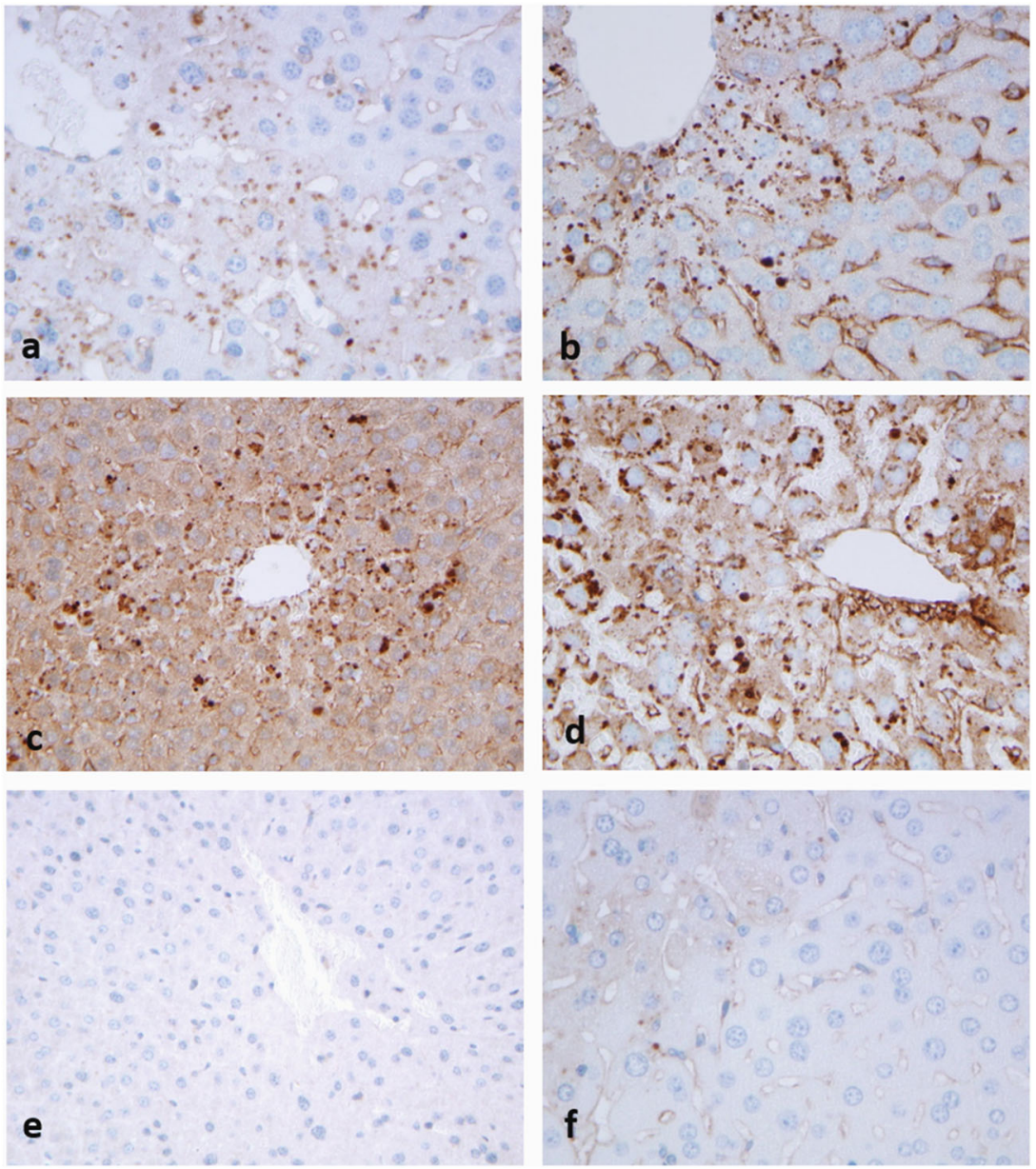
Fig. 5 Effect of BGP-15 on APAP-induced JNK

phosphorylation in mouse liver.

A. Western blot using specific antibodies as indicated, protein lysate from liver tissues. Mice were treated i.p. with APAP

$(450 \mathrm{mg} / \mathrm{kg})$ and BGP

$(100 \mathrm{mg} / \mathrm{kg})$ alone, or in combination for $6 \mathrm{~h}$. Liver homogenates were prepared and phosphorylation and expression levels of c-Jun $\mathrm{N}$-terminal kinase (JNK) were investigated by western blot analysis by using specific antibodies against phosphorylated (upper panel) and total (middle panel) JNK. The picture shows typical blot images obtained in one of the four independent experiments, each including three parallels. The results were quantified by densitometry, normalized to GAPDH (lower panel) and expressed as relative band densities in the percentage of APAP-treated. Data are shown as mean values \pm S.D.; $n=7-12$;

$* P<0.005$, v.s. untreated control:' $P<0.005$, v.s. APAPtreated. B.

Immunohistochemistry with antibody against $\mathrm{p}-\mathrm{JNK}$. Severely injured hepatocytes are highlighted by dark brown stained areas after APAPtreatment (a) as compared to the BGP15-treated (b) and untreated control (c). After APAP+BGP15treatment only few brown granules can be seen (arrow) (d). (formalin fixation, paraffin embedding, hematoxylin staining, (150X)
A
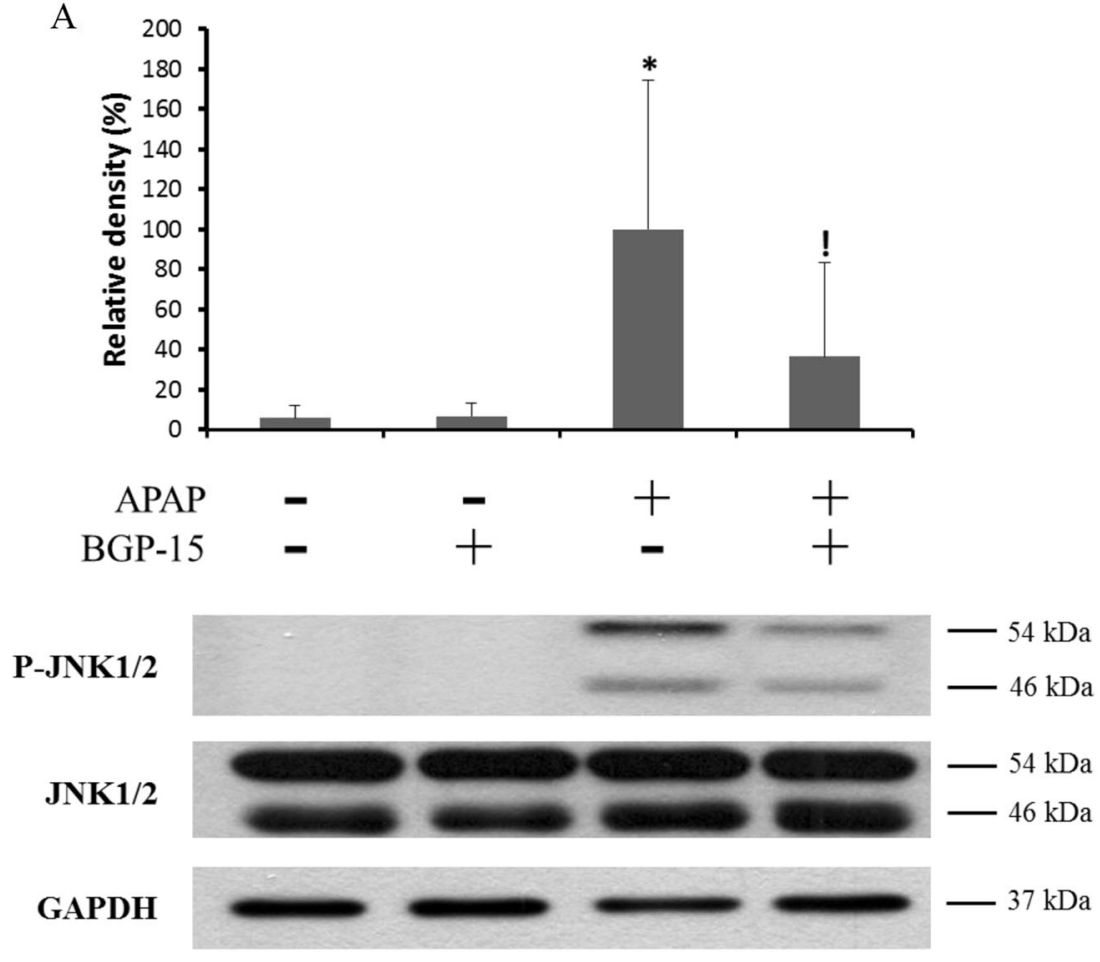

B

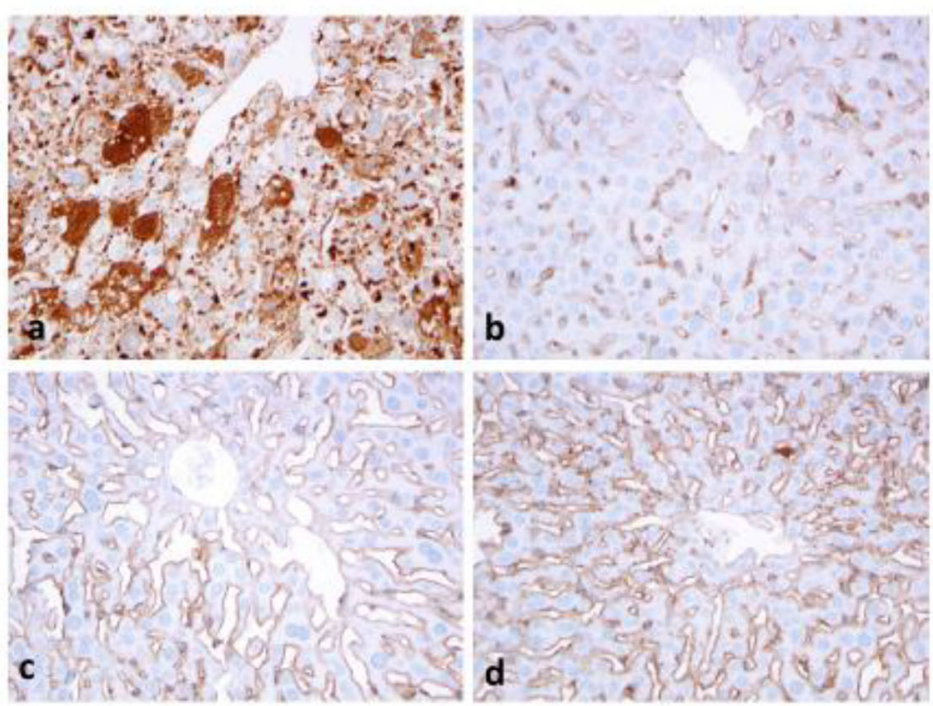

(Fig. 3b) livers were more like those of the control animals (Fig. $3 c$ ) and only very few brown granules were observed in the APAP+BGP15-treated livers (Fig. 3d).

Parallel FFPE sections were used to detect autophagy markers in APAP-treated livers as compared to TOMM20 (Fig. 4a). Immunohistochemical reaction to autophagy markers beclin1 (Fig. 4b), LC3 (Fig. 4c) and p62 (Fig. 4d) presented granular positive reaction in the hepatocytes, in similar centrolobular localization as TOMM20. In contrast no positive reactions could be detected in the control livers
(Fig. 4e), and only few granules could be seen in the APAP+ BGP15-treated hepatocytes (Fig. 4f).

\section{Effect of BGP-15 Administration on JNK Activation}

The level of JNK phosphorylation as an indicator of the activation of stress kinases was investigated in the liver samples by western blot analysis (Fig. 5a). Consistent with previous observations, a dramatic, nearly 20-fold increase in phosphorylated JNK level was found in the livers of mice after a sub-lethal 
APAP treatment. BGP-15 alone did not cause any significant change in JNK phosphorylation, however, co-treatment with BGP-15 remarkably reduced the JNK activating effect of APAP in the mouse liver, i.e. the increase in phosphorylation was only 6-fold in the BGP-15 co-treated animals (Fig. 5a).

After APAP administration, pJNK immunohistochemical reaction was strongly positive (Fig. 5a.), as compared with the BGP15-treated (Fig.5b) and untreated control (Fig. 5c). APAP+BGP-15 treatment resulted in a decreased reaction, only few granules of various sizes were detected in the hepatocytes (Fig. 5d).

\section{Discussion}

Our data presented in this paper further support the protective mitochondrial effects of BGP-15 in acute APAP overdose induced liver injury, which was demonstrated in our previous paper [5]. BGP-15 greatly improves mitochondrial morphology and causes a marked decrease in the number of damaged mitochondria. The attenuation of mitochondrial damage by BGP-15 is further demonstrated by immunohistochemical methods. These changes are accompanied by the parallel increase or decrease of autophagy markers.

Originally, BGP-15 was introduced as an inducer of heat shock proteins (hsp) [26] and various recently published BGP15 effects were also coupled to hsp induction $[18,20]$. These BGP-15 effects make the drug potentially effective in influencing also endoplasmic reticulum (ER) stress related phenomena [22]. However, several effects of BGP-15 can be hardly explained solely by its hsp inducer actions [21].

The presented findings highlight the improvement of mitochondrial functions as a mechanism underlying the beneficial effects of BGP-15. As a result of the oxidative stress, JNK 1 and 2 are activated [27]. Then the phosphorylated (activated) $\mathrm{JNK}$ translocates to the mitochondrial membrane and generates further mitochondrial oxidative stress that triggers the opening of MPT pore, which can finally lead to cell death [28, 29].

Observations published recently suggest that BGP-15 affects mitochondrial fusion-fission cycle, preventing mitochondrial fragmentation [23]. In accordance with these observations, BGP-15 administration results in a decrease in the number of damaged mitochondria as it has been demonstrated in our recent study, which is accompanied with the increase in mitophagy. The central role of mitochondria in apoptosis has long been known, and the participation of mitochondrial proapoptotic factors in ER-derived apoptosis has also been revealed. The increased number of apoptotic cells without a simultaneous activation of effector caspases highlights the role of caspase-independent mechanisms in APAP-induced acute hepatotoxicity [30].

Mitochondrial dysfunction and autophagy are involved in a number of acute and chronic liver diseases, as drug induced liver injury, fatty liver or hepatocellular carcinoma [31]. BGP15 has been shown to affect various model liver injuries, as acetaminophen overdose induced liver damage and tumour formation in murine hepatoma xenografts $[5,32,33]$. Our recent data further confirm mitoprotective mechanism of BGP-15 action in an accordance with parallel changes in mitophagy in acetaminophen overdose induced liver injury.

Authors Contribution FS and TS performed the experiments, ZS evaluated the morphological data, MC, BS and AS checked the results, JM designed and coordinated the study, JM and ZS wrote the manuscript, JM accepts full responsibility for the work.

All authors have read and approved the final manuscript.

Funding Information Open access funding provided by Semmelweis University (SE). This work was supported by the following grants: OTKA K 123752, 129593 and the Hungarian Széchenyi plan GOP1.1.1-2012-0405.

\section{Compliance with Ethical Standards}

Conflict of Interest FS, TS, MC, ZS and AS declare that they have no conflict of interest with respect to the research, authorship, and/or publication of this article. BS and JM are coauthors of patents on mitochondrial effects of BGP-15.

Open Access This article is distributed under the terms of the Creative Commons Attribution 4.0 International License (http:// creativecommons.org/licenses/by/4.0/), which permits unrestricted use, distribution, and reproduction in any medium, provided you give appropriate credit to the original author(s) and the source, provide a link to the Creative Commons license, and indicate if changes were made.

\section{References}

1. Moynihan R (2002) FDA fails to reduce accessibility of paracetamol despite 450 deaths a year - Confidential documents from the US Food and Drug Administration suggest that the agency has avoided a debate on tough new measures to reduce overdoses from painkillers-to avoid offending the pharmaceutical industry. Br Med J 325:678-678. https://doi.org/10.1136/bmj.325.7366.678

2. Lancaster EM, Hiatt JR, Zarrinpar A (2015) Acetaminophen hepatotoxicity: an updated review. Arch Toxicol 89:193-199. https:// doi.org/10.1007/s00204-014-1432-2

3. Jaeschke H (2015) Acetaminophen: dose-dependent drug hepatotoxicity and acute liver failure in patients. Dig Dis 33:464-471. https://doi.org/10.1159/000374090

4. Nagy G, Kardon T, Wunderlich L, Szarka A, Kiss A, Schaff Z, Banhegyi G, Mandl J (2007) Acetaminophen induces ER dependent signaling in mouse liver. Arch Biochem Biophys 459:273279. https://doi.org/10.1016/j.abb.2006.11.021

5. Nagy G, Szarka A, Lotz G, Doczi J, Wunderlich L, Kiss A, Jemnitz K, Veres Z, Banhegyi G, Schaff Z, Sumegi B, Mandl J (2010) BGP15 inhibits caspase-independent programmed cell death in acetaminophen-induced liver injury. Toxicol Appl Pharmacol 243: 96-103. https://doi.org/10.1016/j.taap.2009.11.017

6. Lorincz T, Jemnitz K, Kardon T, Mandl J, Szarka A (2015) Ferroptosis is involved in acetaminophen induced cell death. Pathol Oncol Res 21: 1115-1121. https://doi.org/10.1007/s12253-015-9946-3

7. Qiu Y, Benet LZ, Burlingame AL (1998) Identification of the hepatic protein targets of reactive metabolites of acetaminophen 
in vivo in mice using two-dimensional gel electrophoresis and mass spectrometry. J Biol Chem 273:17940-17953

8. McGill MR, Williams CD, Xie Y, Ramachandran A, Jaeschke H (2012) Acetaminophen-induced liver injury in rats and mice: comparison of protein adducts, mitochondrial dysfunction, and oxidative stress in the mechanism of toxicity. Toxicol Appl Pharmacol 264: 387-394. https://doi.org/10.1016/j.taap.2012.08.015

9. Manyike PT, Kharasch ED, Kalhorn TF, Slattery JT (2000) Contribution of CYP2E1 and CYP3A to acetaminophen reactive metabolite formation. Clin Pharmacol Ther 67:275-282. https:// doi.org/10.1067/mcp.2000.104736

10. Tirmenstein MA, Nelson SD (1989) Subcellular binding and effects on calcium homeostasis produced by acetaminophen and a nonhepatotoxic regioisomer, 3 '-hydroxyacetanilide, in mouse liver. J Biol Chem 264:9814-9819

11. McGill MR, Jaeschke H (2013) Metabolism and disposition of acetaminophen: recent advances in relation to hepatotoxicity and diagnosis. Pharm Res 30:2174-2187. https://doi.org/10.1007/ s11095-013-1007-6

12. Meyers LL, Beierschmitt WP, Khairallah EA, Cohen SD (1988) Acetaminophen-induced inhibition of hepatic mitochondrial respiration in mice. Toxicol Appl Pharmacol 93:378-387

13. Jaeschke H (1990) Glutathione disulfide formation and oxidant stress during acetaminophen-induced hepatotoxicity in mice in vivo: the protective effect of allopurinol. J Pharmacol Exp Ther 255:935-941

14. Cover C, Mansouri A, Knight TR, Bajt ML, Lemasters JJ, Pessayre D, Jaeschke H (2005) Peroxynitrite-induced mitochondrial and endonuclease-mediated nuclear DNA damage in acetaminophen hepatotoxicity. J Pharmacol Exp Ther 315:879-887. https://doi. org/10.1124/jpet.105.088898

15. Seki E, Brenner DA, Karin M (2012) A liver full of JNK: signaling in regulation of cell function and disease pathogenesis, and clinical approaches. Gastroenterology 143:307-320. https://doi.org/10. 1053/j.gastro.2012.06.004

16. Green DR, Galluzzi L, Kroemer G (2014) Cell biology. Metabolic control of cell death. Science 345:1250256. https://doi.org/10.1126/ science. 1250256

17. Bajt ML, Cover C, Lemasters JJ, Jaeschke H (2006) Nuclear translocation of endonuclease $\mathrm{G}$ and apoptosis-inducing factor during acetaminophen-induced liver cell injury. Toxicol Sci 94:217-225. https://doi.org/10.1093/toxsci/kfl077

18. Chung J, Nguyen AK, Henstridge DC, Holmes AG, Chan MH, Mesa JL, Lancaster GI, Southgate RJ, Bruce CR, Duffy SJ, Horvath I, Mestril R, Watt MJ, Hooper PL, Kingwell BA, Vigh L, Hevener A, Febbraio MA (2008) HSP72 protects against obesityinduced insulin resistance. Proc Natl Acad Sci U S A 105:17391744. https://doi.org/10.1073/pnas.0705799105

19. Henstridge DC, Bruce CR, Drew BG, Tory K, Kolonics A, Estevez E, Chung J, Watson N, Gardner T, Lee-Young RS, Connor T, Watt MJ, Carpenter K, Hargreaves M, McGee SL, Hevener AL, Febbraio MA (2014) Activating HSP72 in rodent skeletal muscle increases mitochondrial number and oxidative capacity and decreases insulin resistance. Diabetes 63:1881-1894. https://doi.org/ $10.2337 / \mathrm{db} 13-0967$

20. Gehrig SM, van der Poel C, Sayer TA, Schertzer JD, Henstridge DC, Church JE, Lamon S, Russell AP, Davies KE, Febbraio MA, Lynch GS (2012) Hsp72 preserves muscle function and slows progression of severe muscular dystrophy. Nature 484:394-398. https://doi.org/10.1038/nature10980

21. Sapra G, Tham YK, Cemerlang N, Matsumoto A, Kiriazis H, Bernardo BC, Henstridge DC, Ooi JY, Pretorius L, Boey EJ, Lim L, Sadoshima J, Meikle PJ, Mellet NA, Woodcock EA, Marasco S, Ueyama T, Du XJ, Febbraio MA, McMullen JR (2014) The small- molecule BGP-15 protects against heart failure and atrial fibrillation in mice. Nat Commun 5:5705. https://doi.org/10.1038/ncomms6705

22. Wu LL, Russell DL, Wong SL, Chen M, Tsai TS, St John JC, Norman RJ, Febbraio MA, Carroll J, Robker RL (2015) Mitochondrial dysfunction in oocytes of obese mothers: transmission to offspring and reversal by pharmacological endoplasmic reticulum stress inhibitors. Development 142:681-691. https://doi. org/10.1242/dev.114850

23. Szabo A, Sumegi K, Fekete K, Hocsak E, Debreceni B, Setalo G Jr, Kovacs K, Deres L, Kengyel A, Kovacs D, Mandl J, Nyitrai M, Febbraio MA, Gallyas F Jr, Sumegi B (2018) Activation of mitochondrial fusion provides a new treatment for mitochondria-related diseases. Biochem Pharmacol 150:86-96. https://doi.org/10.1016/j. bcp.2018.01.038

24. Farkas B, Magyarlaki M, Csete B, Nemeth J, Rabloczky G, Bernath S, Literati Nagy P, Sumegi B (2002) Reduction of acute photodamage in skin by topical application of a novel PARP inhibitor. Biochem Pharmacol 63:921-932

25. Literati-Nagy B, Kulcsar E, Literati-Nagy Z, Buday B, Peterfai E, Horvath T, Tory K, Kolonics A, Fleming A, Mandl J, Koranyi L (2009) Improvement of insulin sensitivity by a novel drug, BGP-15, in insulin-resistant patients: a proof of concept randomized doubleblind clinical trial. Horm Metab Res 41:374-380. https://doi.org/10. 1055/s-0028-1128142

26. Vigh L, Literati PN, Horvath I, Torok Z, Balogh G, Glatz A, Kovacs E, Boros I, Ferdinandy P, Farkas B, Jaszlits L, Jednakovits A, Koranyi L, Maresca B (1997) Bimoclomol: a nontoxic, hydroxylamine derivative with stress protein-inducing activity and cytoprotective effects. Nat Med 3:1150-4.27

27. Han D, Dara L, Win S, Than TA, Yuan L, Abbasi SQ, Liu ZX, Kaplowitz N (2013) Regulation of drug-induced liver injury by signal transduction pathways: critical role of mitochondria. Trends Pharmacol Sci 34:243-253. https://doi.org/10.1016/j.tips.2013.01.009

28. Hanawa N, Shinohara M, Saberi B, Gaarde WA, Han D, Kaplowitz N (2008) Role of JNK translocation to mitochondria leading to inhibition of mitochondria bioenergetics in acetaminopheninduced liver injury. J Biol Chem 283:13565-13577. https://doi. org/10.1074/jbc.M708916200

29. Kon K, Kim JS, Jaeschke H, Lemasters JJ (2004) Mitochondrial permeability transition in acetaminophen-induced necrosis and apoptosis of cultured mouse hepatocytes. Hepatology 40:1170-1179. https://doi.org/10.1002/hep.20437

30. Gujral JS, Knight TR, Farhood A, Bajt ML, Jaeschke H (2002) Mode of cell death after acetaminophen overdose in mice: apoptosis or oncotic necrosis? Toxicol Sci 67:322-328

31. Czaja MJ, Ding WX, Donohue TM Jr, Friedman SL, Kim JS, Komatsu M, Lemasters JJ, Lemoine A, Lin JD, Ou JH, Perlmutter DH, Randall G, Ray RB, Tsung A, Yin XM (2013) Functions of autophagy in normal and diseased liver. Autophagy. 9(8):1131-1158. https://doi.org/10.4161/auto.25063

32. Kardon T, Nagy G, Csala M, Kiss A, Schaff Z, Nagy PL, Wunderlich L, Bánhegyi G, Mandl J (2006) Influence of BGP-15, a nicotinic Amidoxime derivative, on the vascularization and growth of murine Hepatoma Xenografts. Anticancer Res 26:1023-1028

33. Du K, Williams CD, McGill MR, Jaeschke H (2014) Lower susceptibility of female mice to acetaminophen hepatotoxicity: role of mitochondrial glutathione, oxidant stress and c-Jun N-terminal kinase. Toxicol Appl Pharmacol 281:58-66. https://doi.org/10.1016/ j.taap.2014.09.002

Publisher's Note Springer Nature remains neutral with regard to jurisdictional claims in published maps and institutional affiliations. 